\title{
Pesquisa de Satisfação de Clientes: o Estado-da-Arte e Proposição de um Método Brasileiro
}

\author{
Carlos Alberto Vargas Rossi \\ Luiz Antonio Slongo
}

\section{RESUMO}

Este artigo traz à discussão o momentoso tema da satisfação de clientes. Para tanto, discute-se a importância e a oportunidade das pesquisas de medição de satisfação de clientes, o seu estadoda-arte, a apresentação detalhada do método concebido e utilizado no Brasil pelos autores deste trabalho, bem como suas limitações e implicações futuras para pesquisa. No desenvolvimento do artigo, tem-se o exame da literatura mais atualizada sobre satisfação de clientes e a descrição pormenorizada do método brasileiro desenvolvido pelos autores. Chega-se, ao longo do trabalho, à oferta de um método de pesquisa de satisfação de clientes que deriva da consideração do estado-da-arte sobre o tema, da experiência acumulada pelos autores em ensino, pesquisa e consultoria e pela realização de benchmarking em empresas pioneiras e reputadas nas práticas dessas pesquisas no Brasil.

Palavras-chaves: satisfação do cliente; pesquisa de satisfação de clientes; comportamento do consumidor.

\begin{abstract}
This article presents a discussion about the important and quite up-to-date theme: customer satisfaction. In order to do that, one discusses the relevance and the opportunity of the survey for measuring customer satisfaction and its state of the art, presents in deails a method conceived and applied in Brazil by this paper's authors, and analyses method's limitations and its future implications in research. In the development of the paper, one has examined the most up-to-date literature about customer satisfaction and the datailed description of a Brazilian method developed by the authors. Along the work, it is raised a survey's method on customer satisfaction which has derived from the analysis of theme's state of the art, the authors' experience in teaching, researching and consulting, as well as the benchmarking some their great experience on that.
\end{abstract}

Key words: customer satisfaction; customer satisfaction research; consumer behavior. 


\section{INTRODUÇĀO}

Pesquisa de satisfação de clientes é um sistema de administração de informações que continuamente capta a voz do cliente, através da avaliação da performance da empresa a partir do ponto de vista do cliente. Esta pesquisa, assim, mede a qualidade externa ou performance da empresa em seus negócios, indicando caminhos para as decisões futuras de comercialização e marketing.

Mais importante, ainda, é a relação verificada nas empresas entre altos níveis de satisfação de clientes e retornos econômicos superiores. Hoje, há amplo suporte empírico para comprovar que elevados escores de satisfação dos clientes são acompanhados por uma rentabilidade acima da média (Reicheld e Sasser, 1990; Fornell, 1992; Anderson, Fornell e Lehmann, 1994).

Há, também, vários outros benefícios proporcionados pela pesquisa de satisfação de clientes: percepção mais positiva dos clientes quanto à empresa; informações precisas e atualizadas quanto às necessidades dos clientes; relações de lealdade com os clientes, baseadas em ações corretivas; e confiança desenvolvida em função de maior aproximação com o cliente.

Como professores e consultores temos estudado e praticado a pesquisa de satisfação de clientes. Neste trabalho, expressamos nossa visão sobre o assunto, destacando, principalmente, aspectos relacionados à importância da pesquisa de satisfação de clientes para as empresas, ao exame do estado-da-arte do tema e ao método por nós utilizado para realização deste tipo de pesquisa.

\section{Importância da Pesquisa de Satisfação de Clientes}

As informações sobre os níveis de satisfação dos clientes constituem uma das maiores prioridades de gestão nas empresas comprometidas com qualidade de seus produtos e serviços e, por conseguinte, com os resultados alcançados junto a seus clientes.

Intimamente ligada aos processos de qualidade, que fortalecem a competitividade das empresas, a pesquisa sobre a satisfação de clientes insere-se entre os prérequisitos que sustentam ações eficazes de marketing. $O$ estreito relacionamento entre marketing e qualidade evidencia-se a partir dos próprios conceitos de qualidade total. Kaoru Ishikawa, um dos autores pioneiros na área da qualidade total, 
popularizou a máxima de que "o marketing é a porta de entrada e de saída da qualidade".

O objetivo da administração da qualidade consiste em alavancar a produtividade e a competitividade da empresa, maximizando sua rentabilidade. A avaliação da qualidade é realizada, quantitativamente, por meio de índices que medem resultados da empresa em vários de seus processos. Esses indicadores de qualidade são aferidos por entidades que certificam (ISO 9000, por exemplo) e premiam companhias em todo o mundo.

O reconhecimento de patamares diferenciados alcançados pelas empresas em qualidade passa, inexoravelmente, pelo atingimento de níveis igualmente superiores nas relações com os clientes. A importância do conhecimento relacionado à satisfação dos clientes da empresa, neste contexto, manifesta-se pelo peso atribuído ao item satisfação do cliente nos critérios usados para julgar anualmente a qualidade das companhias norte-americanas no Prêmio Malcolm Baldridge e das companhias japonesas no Prêmio Deming.

No Brasil, o Prêmio Nacional da Qualidade (PNQ) foi instituído em 1992, seguindo os critérios do Prêmio Malcolm Baldridge. O PNQ está a cargo da Fundação para o Prêmio Nacional da Qualidade, cujos itens e pontuação máxima, atualmente adotados em seu critério de avaliação, são apresentados no Quadro 1 a seguir.

Observa-se, pelo conteúdo do Quadro 1, que do total de 1000 pontos utilizados para avaliar a qualidade das companhias brasileiras, os itens relacionados à satisfação do cliente (relacionamento com o cliente e medição de sua satisfação ; resultados relativos à satisfação dos clientes) somam 170 pontos, $17 \%$ do total. Se considerado isoladamente, $o$ item 7.1 (resultados relativos à satisfação dos clientes) corresponde a 130 pontos que, ao lado dos resultados financeiros e relativos ao mercado e resultados operacionais e relativos à qualidade do produto corresponde à maior pontuação individual. Não resta dúvida, portanto, de que a excelência em pesquisa sobre a satisfação dos clientes é um importante pré-requisito para a conquista do PNQ brasileiro.

Além dessas informações, a importância de um trabalho de tal natureza é reforçada pelo caráter estratégico possuído pelas pesquisas sobre satisfação de clientes, uma vez que fornecem o conhecimento essencial para a construção e sedimentação das vantagens competitivas das empresas. 


\section{Quadro 1: Lista dos Critérios, Itens e Pontuações Máximas}

\begin{tabular}{|c|c|}
\hline Critérios e Itens & Pontuação máxima \\
\hline 1. Liderança: & 110 \\
\hline 1.1. Sistema de liderança & 80 \\
\hline 1.2. Responsabilidade pública e cidadania & 30 \\
\hline 2. Planejamento estratégico: & 80 \\
\hline 2.1. Processo de desenvolvimento e de desdobramento da estratégia & 40 \\
\hline 2.2. Estratégia e planos da organização & 40 \\
\hline 3. Foco no cliente e no mercado: & 80 \\
\hline 3.1. Conhecimento sobre o cliente e o mercado & 40 \\
\hline 3.2. Relacionamento com o cliente e medição de sua satisfação & 40 \\
\hline 4. Informação e análise: & 80 \\
\hline 4.1. Gestão das informações relativas à organização & 25 \\
\hline 4.2. Gestão das informações comparativas & 15 \\
\hline 4.3. Análise crítica do desempenho da organização & 40 \\
\hline 5. Desenvolvimento e gestão de pessoas: & 100 \\
\hline 5.1. Sistemas de trabalho & 40 \\
\hline 5.2. Educação, treinamento e desenvolvimento dos funcionários & 30 \\
\hline 5.3. Bem-estar e satisfação dos funcionários & 30 \\
\hline 6. Gestão de processos: & 100 \\
\hline 6.1. Gestão de processos relativos ao produto & 60 \\
\hline 6.2. Gestão de processos de apoio & 20 \\
\hline 6.3. Gestão de processos relativos aos fornecedores e às parcerias & 20 \\
\hline 7. Resultados do negócio: & 450 \\
\hline 7.1. Resultados relativos à satisfação dos clientes & 130 \\
\hline 7.2. Resultados financeiros e relativos ao mercado & 130 \\
\hline 7.3. Resultados relativos aos funcionários & 35 \\
\hline 7.4. Resultados relativos aos fornecedores e parceiros & 25 \\
\hline 7.5. Resultados operacionais e relativos à qualidade do produto & 130 \\
\hline TOTAL DE PONTOS & 1000 \\
\hline
\end{tabular}

Fonte: Fundação para o Prêmio Nacional da Qualidadde (1997) 


\section{Estado-da-Arte em Satisfação de Clientes}

A pesquisa de satisfação de clientes, segundo Evrard (1994), exibe dois marcos históricos: o mês de abril de 1976, quando ocorreu em Chicago a primeira conferência especializada sobre o tema, com o apoio do Marketing Science Institute e da National Science Foundation; e os artigos seminais de Hunt (1977) e Day (1982). Foi na década de 80, no entanto, que se deram os avanços mais significativos, tanto no nível macro quanto no nível micro. O nível macro refere-se aos estudos voltados às comparações intersetoriais das relações entre a satisfação dos consumidores e a estrutura dos mercados, fornecendo subsídios para a própria formulação de políticas públicas. Destacam-se aqui, principalmente, os trabalhos dos pesquisadores da Universidade de Michigan (Ann Arbor), comandados pelo Professor Claes Fornell. O nível micro, por seu turno, volta-se para os interesses das empresas no conhecimento da satisfação de seus clientes. O crescimento desses interesses deveu-se, com maior intensidade a partir dos anos 80 , à consciência de que a satisfação dos clientes é uma variável-chave de seus comportamentos posteriores (recompra, lealdade, propaganda boca-a-boca favorável etc) e, também, pelo impulso dos programas de qualidade total, em que a satisfação dos clientes representa a faceta de marketing (Evrard, 1994).

\section{Conceitos de Satisfação de Clientes}

Afora o escopo do tema, eleva-se a sua dimensão conceitual. A satisfação do cliente possui dois conceitos essenciais: satisfação específica em uma transação e satisfação acumulada (Boulding et al., 1993). Os pesquisadores de marketing e do consumidor concordam no que tange à satisfação como medida individual, transação-específica ou como avaliação de uma experiência particular com certo produto ou serviço. Nesse caso, a visão de satisfação como algo transação-específica é útil para os encontros particulares e de curto prazo com um produto ou serviço. Não se observa tal convergência, no entanto, quando a discussão recai sobre a questão de quem vem primeiro, ou, mais propriamente, qual é o antecendente: a qualidade percebida do serviço ou a satisfação transação-específica? Este artigo não se ocupará desse debate. Assumirá a visão de Johnson, Anderson e Fornell (1995) de que a satisfação é cumulativa; é constructo abstrato que descreve a experiência total de consumo com um produto ou serviço.

A adoção desse conceito de satisfação "é mais consistente com as visões existentes na psicologia econômica, em que a satisfação é igualada com a noção subjetiva de bem-estar (Van Raaij, 1981; Wärneryd, 1988) e na economia, onde a satisfação vai além da utilidade econômica esperada e encampa a utilidade do consumo pós-compra" (Johnson, Anderson e Fornell, 1995). Sob um ponto-de- 
vista mais aplicado ou gerencial, a satisfação acumulada é mais atraente, porque fornece uma indicação clara (e fundamental) da performance atual e de longo prazo de uma empresa ou mercado. Esse posicionamento teórico é crucial na construção do presente artigo, que tem entre seus objetivos apresentar um método de pesquisa de satisfação de clientes estruturado exatamente sobre este alicerce teórico.

\section{Tipos de Estudo de Satisfaçăo de Clientes}

A forma de se conduzir as pesquisas de satisfação de clientes abre-se, a partir dessas considerações teóricas iniciais, em dois caminhos: os estudos experimentais e os estudos com perspectiva agregada. A tradição experimental estabelecida na Psicologia evoca as origens da pesquisa de satisfação de clientes. Ao mesmo tempo, oferece-se como uma das vias para os estudos de satisfação de clientes, com foco sobre medidas individuais de sujeitos, eventos ou estímulos. Os estudos experimentais fornecem um nível de detalhe essencial para entender a natureza e os antecedentes da satisfação, mas não necessariamente geram generalizações empíricas (Johnson, 1995). Dizendo de outra forma, esses estudos, em nível individual, realmente demonstram a amplitude de possíveis fenômenos comportamentais, mas, como uma vasta linhagem de psicólogos experimentais têm reconhecido ao longo do tempo (Wärneryd, 1988), permanecem as dificuldades de obter generalizações a partir de seus achados.

Apenas os estudos de satisfação de clientes com perspectiva agregada (ou estudos em nível do mercado) são capazes de produzir as generalizações empíricas. "De um ponto-de-vista científico, a pesquisa sobre satisfação se robustece quando se faz a adição das análises ao nível do mercado aos estudos ao nível individual" (Johnson, Anderson e Fornell, 1995, p. 695). Os estudos em nível de mercado se viabilizam com a utilização das quatro faces da agregação de Epstein (1980): estímulos, ocasiões de uso, modos de medição e indivíduos. A agregação incorpora um nível de perspectiva macropsicológica sobre a satisfação do cliente, que passa a ser uma experiência acumulada (e não mais isolada) com um produto ou serviço (Johnson, 1995). "Essa agregação serve, ainda, para reduzir o erro na medição de variáveis-chaves relacionadas com a satisfação e, também, para aumentar o estabelecimento de relações coerentes com outras variáveis (como, por exemplo, intenções de compra e lealdade do cliente)" (Johnson, Anderson e Fornell, 1995, p. 695).

Outra evidência da importância das pesquisas com perspectiva agregada é que os resultados de satisfação em nível de mercado são um forte indicador da retenção agregada do cliente pela empresa e, ainda, da futura rentabilidade (Anderson, Fornell e Lehmann, 1994). Esses resultados oferecem-se, então, como cintilante referência para as empresas que procuram acelerar sua performance de negócios, 
e para administradores públicos que queiram monitorar o bem-estar dos consumidores.

\section{Índices Nacionais e Setoriais de Satisfação de Clientes}

Atualmente, realçam-se entre os modelos de satisfação, nessa perspectiva agregada, os índices nacionais de satisfação de clientes. Como ilustração, utilizaremos o índice norte-americano: o American Customer Satisfaction Index (ACSI).

O ACSI é uma medida de desempenho, baseada no mercado, para empresas, indústrias, setores econômicos e economias nacionais. A teoria que fundamenta $\mathrm{o}$ modelo do ACSI tem três antecedentes: a qualidade ou performance percebida, $\mathrm{o}$ valor percebido e a expectativa do cliente. As conseqüências do aumento da satisfação do cliente, que é aferida pelo ACSI, apontam para a redução das reclamações e para o incremento da lealdade do cliente (Fornell et al., 1996).

O método do ACSI foi concebido para ser representativo da economia do país como um todo. Para tanto, os sete principais setores econômicos dos Estados Unidos têm seus clientes finais pesquisados. Esses sete setores são: (1) indústrias de bens não duráveis (cigarros, cerveja, tênis esportivos, gasolina etc); (2) indústrias de bens duráveis (automóveis, computadores pessoais, eletroeletrônicos etc); (3) transportes/comunicações/utilidades (linhas aéreas, redes de televisão, serviços postais etc); (4) varejo (lojas de departamento, restaurantes, redes de fast food, supermercados etc); (5) setor financeiro/seguros (bancos comerciais, seguradoras etc); (6) serviços (hospitais, hotéis etc); e (7) administração pública/Governo (transportes coletivos, polícia etc). Em cada um desses sete setores, as maiores empresas, por volume de vendas, são incluídas na pesquisa. E, para cada uma dessas empresas, aproximadamente 250 clientes atuais são entrevistados, a partir de amostras probabilísticas de domicílios obtidas em relações de domicílios norte-americanos com telefone, que representam $95 \%$ dos lares em todo o país.

Cada questionário aplicado a esses clientes contém as mesmas 17 questões estruturadas e 8 questões demográficas. $\mathrm{O}$ fraseado e os exemplos são ajustados aos produtos e serviços especificamente avaliados. As 15 variáveis medidas, por sua vez, referem-se às variáveis latentes de (a) expectativas do cliente - 3 variáveis; (b) qualidade percebida - 3 variáveis; (c) valor percebido - 2 variáveis; (d) o próprio ACSI - 3 variáveis; (e) reclamações do cliente - 1 variável; e (f) lealdade do cliente - 3 variáveis (Fornell et al., 1996).

É utilizada uma escala de 10 pontos no questionário, a fim de pemitir que os clientes façam melhor discriminação em suas respostas. Outro objetivo da escala com 10 pontos é reduzir os problemas estatísticos de distorção nas respostas (Fornell, 1992). 
Os resultados nacionais do ACSI, a título de ilustração, têm piorado desde sua primeira verificação no terceiro trimestre de 1994 (índice nacional de 74,5\%), chegando a 72,4\% no segundo trimestre de 1996. Essa piora, segundo Fornell et al. (1996), deve-se às quedas verificadas nos índices de serviços combinadas com o crescimento do setor de serviços na economia norte-americana. Importa registrar que todos os sete setores apresentam índices próprios, assim como todas as indústrias (subsetores) e todas as empresas pesquisadas.

Uma apresentação geral desses índices pode ser apreciada na matéria da revista Fortune de dezembro de 1995.

Além do ACSI, outros índices nacionais precisam ser comentados. O Sweden Customer Satisfaction Barometer (SCSB) foi o primeiro, existindo desde 1989. O Deustsch Kunderbarometer começou, em 1992, a medir nacionalmente os índices de satisfação de clientes na Alemanha. Mais recentemente, em 1996, também Taiwan e a Nova Zelândia instituíram seus índices nacionais (Fornell et al., 1996).

\section{O Papel do Paradigma da Desconfirmaçăo na Satisfaçăo do Cliente}

Uma excelente revisão teórica de toda a evidência empírica do impacto da desconfirmação de expectativas foi realizada por Yi (1991).

Mais recentemente, uma crítica à supremacia absoluta do paradigma da desconfirmação apareceu no instigante trabalho de Spreng, MacKenzie e Olshavsky (1996), ao reexaminarem os determinantes da satisfação do consumidor. Ao apresentarem um novo modelo do processo de formação da satisfação, os autores vão além do paradigma da desconfirmação ao incluírem nesse processo os desejos do consumidor e verificando, também, o impacto da comunicação de marketing (através da idéia da satisfação com a informação). O novo modelo foi testado empiricamente e confirmou as hipóteses de existência de relacionamento entre os desejos do consumidor e sua satisfação, permitindo afirmar que a satisfação geral do consumidor decorre tanto da congruência de seus desejos quanto da desconfirmação positiva de suas expectativas. Este tema incandesceu ainda mais a polêmica que Teas $(1993,1994)$ e a dupla Cronin Jr. e Taylor (1992) estabeleceram em relação ao modelo SERVQUAL de avaliação da qualidade em serviços. No epicentro dessa discussão está a necessidade (ou não) de incluir as expectativas dos clientes na aferição de qualidade, com as conseqüentes repercussões nas avaliações de satisfação de clientes. Como é sabido, esses três autores defendem, com base em testes de seus modelos, que não é necessário incluir as expectativas nas referidas avaliações.

Percebe-se, assim, que as pesquisas de medição de satisfação de clientes incluem processos de mensuração que avaliam as expectativas junto com a performance 
e, por outro lado, avaliam a performance sem a necessidade de avaliar também as expectativas.

\section{As Escalas de Medição da Satisfação dos Clientes}

A busca da escala perfeita para medir a satisfação dos clientes tem provocado acesas discussões na literatura recente de marketing. Um eloqüente exemplo desses debates foi o número da revista Marketing Research (1994), que se dedicou inteiramente ao tema. Devlin, Dong e Brown (1993) defenderam a escala de 5 pontos para medir as expectativas e de 4 pontos para os requerimentos dos clientes.

Grapentine (1994, p. 11) argumentou, em contraponto a Devlin, Dong e Brown (1993), que seus dois constructos "têm severos problemas de validade" e que, portanto, o já comentado modelo de Teas da performance avaliada é superior na predição da qualidade percebida. $\mathrm{O}$ argumento, aqui, é que "a escala que mede performance percebida do produto ou serviço pode ser mais preditiva de qualidade global do que uma escala que mede expectativas" (Grapentine, 1994, p. 11).

Wittink e Bayer (1994), por sua vez, apresentaram justificativas para o uso conjunto da escala de 10 pontos na medição da satisfação global, e da escala de 2 pontos na medição de itens individuais. Nesse artigo, os autores compararam, em uma única empresa não especificada, o mencionado uso conjunto das escalas com a utilização da escala de 5 pontos para a medição tanto da satisfação global quanto dos itens individualmente. Como resultado, encontraram superioridade no sistema escala de 10/escala de 2; no entanto afirmaram nas conclusões do trabalho que "os resultados que observamos para essa única empresa não necessariamente se manifestarão em outras empresas. Nós encorajamos vigorosamente outros pesquisadores a fazerem comparações semelhantes e relatarem os seus resultados" (Wittink e Bayer, 1994, p. 21-22).

Schmalensee (1994, p. 24), ao analisar os três trabalhos supracitados, assumiu uma posição de síntese ao afirmar que "o número de pontos de uma escala é menos importante do que sua aplicação", ou seja, a seleção dos termos empregados e o número de pontos de uma escala devem ser definidos pelos objetivos da empresa e pelas situações do mercado. Para a autora, nenhuma escala é perfeita em todas as situações. Apresentou, para sustentar essa conclusão, escalas de 2, 4, 5, 7 e 10 pontos, ressaltando as utilidades específicas de cada uma, sempre de acordo com a necessidade de informação da empresa e a situação de mercado.

Assim, conclui-se a respeito das escalas que não existe uma escala ideal que seja capaz de responder, indistintamente, a todas as pesquisas de medição de satisfação de clientes. Importa analisar os propósitos que levam uma empresa a 
conceber um sistema de avaliação da satisfação de seus clientes e, a partir dessa compreensão, elaborar o tipo de escala mais apropriado, o que provavelmente se configure mais confiável e válido.

\section{A Prática das Pesquisas de Satisfaçăo de Clientes nas Empresas}

Tendo considerado o escopo, os conceitos, os tipos de estudo, os modelos e a questão das escalas, pode-se voltar ao cerne do artigo e, antes de apresentar o método proposto pelos autores, retomar o que Evrard (1994) qualificou como nível micro das pesquisas de satisfação de clientes. Localiza-se aqui, conforme já exposto, o enquadramento básico desse trabalho.

A medição de satisfação dos clientes representa hoje, nos Estados Unidos, uma verdadeira indústria. Centenas de empresas de pesquisa são especializadas nesse assunto; conferências nacionais e internacionais são realizadas sistematicamente (Annual Customer Satisfaction and Quality Measurement Conference, organizada pela A.M.A.). A literatura concernente ao tema é abundante, tanto em livros quanto em artigos publicados em journals e revistas. Toda essa efervescência acaba por emprestar indiscutível relevância às pesquisas de satisfação de clientes.

Uma interessante pesquisa sobre essas práticas em empresas norte-americanas foi realizada por Mentzer, Bienstock e Kahn (1995) e publicada na Marketing Management. Apoiada pela AT\&T, a pesquisa verificou as práticas de medição e administração da satisfação de clientes (SC) em 124 grandes empresas, analisando os recursos humanos empregados nas pesquisas, a alocação orçamentária destinada ao programa de SC, a maneira como as questões da pesquisa são formuladas, os tipos de análise de dados usados, os tipos de modelos ou teorias adotados e o uso da informação obtida. Os resultados levaram os autores a relacionar procedimentos capazes de assegurar que o processo de SC da empresa (1) começa com o input qualitativo e quantitativo dos clientes, dos empregados que interagem com esses clientes e com os clientes dos concorrentes; (2) desenvolve planos de ação para melhorar o que os clientes dizem que deve ser melhorado; e (3) motiva e capacita os empregados a satisfazer os clientes, vinculando avaliação de desempenho e compensação com o cumprimento do plano de ação. As empresas com as melhores práticas de $\mathrm{SC}$ registraram os seguintes aspectos em comum:

- os funcionários de marketing e vendas são os principais responsáveis (com o input dos clientes) pela formulação dos programas e questionários de SC;

. a alta administração e a área de marketing lideram os programas;

- a medição envolve uma combinação de métodos de pesquisa qualitativos e quantitativos que incluem, predominantemente, questionários pelo correio, enquetes telefônicas e focus groups; 
. as avaliações incluem tanto a performance de SC da empresa quanto dos concorrentes;

. os resultados são disponibilizados para todos os empregados, mas não necessariamente para os clientes;

. os programas de TQM e SC freqüentemente são vinculados, mas nem sempre;

. a SC está incorporada ao foco estratégico da empresa via declaração da missão empresarial (Mentzer, Bienstock e Kahn, 1995).

Também na Europa constata-se a importância dessa área de marketing e comportamento do consumidor, como demonstra a pesquisa de Boss et al. (1994) na França.

\section{O Método Brasileiro de Pesquisa de Satisfação de Clientes}

O que está relatado neste capítulo do trabalho é resultado de nossas experiências na realização de pesquisas para mensurar satisfação de clientes. Originalmente, o método foi concebido com base em três vertentes: na nossa experiência passada em pesquisa de marketing, na literatura especializada e no benchmarking que realizamos em 1994 junto a empresas pioneiras neste tipo de pesquisa no Brasil, tais como Xerox, IBM, Citibank e Rhodia.

\section{Fases da Pesquisa}

Em uma pesquisa de satisfação de clientes a geração dos indicadores de satisfação reveste-se de extrema importância, uma vez que é deles que resulta a validade deste tipo de pesquisa. Na prática isso significa dizer que o cliente precisará expressar estados de satisfação (e/ou insatisfação) em relação a elementos por ele valorizados nas suas relações com a empresa ofertante: de nada adiantará medir estados de satisfação e/ou insatisfação em relação a elementos para os quais os clientes se mostram indiferentes.

Errar na definição dos indicadores de satisfação corresponde a errar na essência da pesquisa. Por mais perfeito que seja o plano de pesquisa nos seus aspectos de amostragem, procedimentos de coleta, análise e interpretação de resultados, ele sucumbirá se sua base de sustentação estiver fragilizada pela ausência de bons indicadores de satisfação, gerados com base científica.

Embora possa existir forte propensão a fazê-lo, é bom lembrar, também, que a empresa não deve construir o instrumento da pesquisa para medição da satisfação 
de seus clientes em cima de indicadores gerados exclusivamente pelos próprios executivos, ou simplesmente retirados da literatura especializada. Por mais experientes que sejam os executivos, ou por mais profunda e atualizada que seja a literatura, será necessário dotar a pesquisa de características específicas, devidamente sintonizadas com o perfil do cliente cujo grau de satisfação se pretende medir. Trata-se, portanto, de customizar a pesquisa.

Desta forma, as pesquisas de satisfação de clientes apresentam duas fases distintas e bem demarcadas em termos de tempo e de método: a primeira, de natureza exploratória e qualitativa, conduzida com o propósito de gerar os indicadores de satisfação, que fornecerão a base para a elaboração do instrumento de coleta de dados da segunda fase; a segunda, de natureza descritiva e quantitativa, destinada a medir o grau de satisfação dos clientes. A seguir são apresentadas e comentadas estas duas fases.

\section{Fase Exploratória/Qualitativa:}

Os procedimentos metodológicos recomendados nessa fase da pesquisa são os seguintes:

\section{a) Amostra:}

Os elementos que participam dessa fase da pesquisa devem ser, preferencialmente, selecionados dentre a população de clientes da empresa. Sua escolha deverá ser feita conjuntamente pelo pesquisador e por executivos da empresa avaliada, adotando-se critério de escolha por julgamento. É importante que os entrevistados nessa fase apresentem condições de discernir quanto à relevância dos indicadores de satisfação; recomendável, portanto, que sejam dotados de experiência nas relações com fornecedores do setor considerado. Em síntese, eles precisarão ter algo a dizer quanto à geração e relevância de indicadores de satisfação. Por esta razão é que o critério de escolha dos elementos da amostra por julgamento é o mais recomendado.

Outro aspecto normalmente intrigante nessa fase da pesquisa é o número de entrevistados. Como se trata de pesquisa qualitativa, o que deve orientar o pesquisador é a qualidade da amostra e não a quantidade de elementos que a compõe. A homogeneidade de respostas que se obtêm das entrevistas vai determinar, em última instância, o número de entrevistados nessa fase. Se as respostas dos primeiros entrevistados começam a convergir para um mesmo conjunto de indicadores, é sinal de que o número de entrevistas pode ser reduzido. O inverso acontecerá se as respostas forem apresentando divergências. Mesmo assim, recomenda-se que o pesquisador não se satisfaça com duas ou três entrevistas. 
Se for utilizada a técnica da entrevista em profundidade para gerar os indicadores de satisfação (ver item $\mathbf{b}$ abaixo), é recomendável que o pesquisador selecione, inicialmente, entre 15 e 20 clientes para compor essa amostra. Este não é um número cabalístico que vá servir sempre e para qualquer caso; no entanto nossa experiência nesse tipo de pesquisa nos permite inferir que entre estes dois limites está um número bem razoável de entrevistas.

Raciocínio semelhante poderá ser seguido, se a técnica utilizada para a coleta de dados for a do group discussion. A realização de um grupo poderá ser suficiente, se os indicadores gerados emergirem de um consenso entre os integrantes que foram cuidadosamente selecionados para participarem da discussão. Se os resultados indicarem opiniões difusas, é sinal de que outro(s) grupo(s) deverá(ão) ser realizado(s).

b) Coleta dos dados:

Duas técnicas podem ser empregadas para a coleta de dados dessa fase: entrevistas em profundidade e group discussion. Ambas apresentam vantagens e desvantagens que deverão ser avaliadas pelo pesquisador antes de decidirem-se por uma delas.

Nos casos de entrevistas em profundidade, os entrevistados tendem a sentir-se mais confortáveis em responder às questões formuladas. Eles sentem-se menos constrangidos em uma situação um-a-um. De forma mais específica:

- sentem-se menos intimidados com a presença de um único indivíduo - o entrevistador - do que com a presença de todos os membros do grupo, mais o moderador e os observadores, que normalmente compõem um group discussion $^{(1)}$;

- sentem-se menos ansiosos sem a presença de observadores, cuja função não conseguem avaliar direito. Que farão os observadores atrás do espelho? ${ }^{(2)}$ Que pensam, ou o que dizem a seu respeito?;

- reduzem a preocupação com o próprio desempenho; o grupo pode funcionar como instrumento de pressão para que não errem, o que pode provocar inibição ou distorção entre o que pensam e o que expressam verbalmente;

- reduzem, também, a preocupação com etiquetas por liberarem-se da imposição de um comportamento grupal mais rígido e socialmente coercitivo;

- uma interação eu-você, caracterizada em uma entrevista de profundidade, difere de uma interação eu-eles, caracterizada em um group discussion. A primeira é potencialmente íntima, a segunda é associada a risco e a exposição. 
Agrega-se à entrevista em profundidade, ainda, a maior facilidade de obtê-la. $\mathrm{O}$ entrevistado não precisa deslocar-se para responder à entrevista, normalmente o entrevistador vai até ele. No caso do group discussion, é necessário que os participantes se desloquem até um local determinado, adequado à realização do evento, acarretando maior resistência em participar da pesquisa.

As características de uma entrevista em profundidade, por outro lado, exigem preparo especial por parte do entrevistador. Normalmente é necessário algo mais do que um mero treinamento. Não basta que o entrevistador domine a técnica de entrevista; será necessário que ele tenha grande domínio do tema sobre o qual a pesquisa trata e tenha na cabeça os seus objetivos. Por essa razão é recomendável que tais entrevistas sejam conduzidas pelo(s) próprio(s) autor(es) do projeto. Nas pesquisas por nós conduzidas esta tem sido uma tarefa por nós mesmos realizada.

Com relação ao group discussion, deve-se salientar que a chave para o seu sucesso está nas livres intervenções e opiniões de seus membros, o que, no entanto, demanda habilidade do moderador para fazer com que todos participem da discussão, sem que se crie nenhum tipo de ascendência ou dependência entre os participantes. O moderador, portanto, deverá ser um profissional experiente nesse tipo de atividade, normalmente um profissional da psicologia com experiência em dinâmica de grupo. Será indispensável ainda que o moderador esteja devidamente inteirado do tema tratado pela pesquisa e que tenha muito claros os objetivos do trabalho.

Destacam-se como principais vantagens do group discussion:

- a interação entre os membros do grupo conduz à geração de idéias e/ou descobertas que podem não emergir na presença de uma única pessoa;

- a própria experiência que emerge do grupo pode levar a novos pontos de vista dos participantes, que não teriam ensejo em respostas individuais, sem a exposição aos demais membros do grupo;

- os resultados da pesquisa são disponibilizados mais rapidamente; muitos deles podem até ser abstraídos durante a discussão entre os membros do grupo.

c) Análise dos dados:

Tratando-se de pesquisa qualitativa, a análise dessa fase da pesquisa demanda procedimentos pertinentes, destacando-se a análise de conteúdo, em casos de entrevistas em profundidade, ou a interpretação de opiniões e atitudes, no caso de group discussion, expressa no relatório do moderador. Alguns softwares (por exemplo, o Sphinx) podem auxiliar no trabalho de análise de dados dessa fase da pesquisa, através da denominada análise léxica. 
$\mathrm{Na}$ fase de análise e interpretação de resultados dessa fase exploratória da pesquisa, o pesquisador depara-se com algumas dificuldades básicas decorrentes da natureza da investigação, as quais, para serem removidas, demandarão persistência e bom senso. Dentre essas dificuldades podem-se destacar:

- em geral, as respostas dos clientes envolvem uma linguagem própria, não técnica e subjetiva na forma de expressão;

- as condições do cliente no momento em que ele expressa sua opinião acerca dos indicadores de satisfação são susceptíveis de não reproduzir as condições normais de suas relações com a empresa. É importante que o pesquisador, no momento em que analisa as respostas dos clientes, possa neutralizar tais situações.

Independentemente da técnica ou dos recursos empregados para analisar os dados da pesquisa qualitativa, é indispensável que o pesquisador não perca de vista o seu propósito central: geração dos indicadores de satisfação.

d) Envolvimento dos executivos:

Os executivos da empresa avaliada, principalmente os das áreas de marketing e vendas, têm importante papel a desempenhar durante a fase qualitativa da pesquisa de medição da satisfação de clientes. Inicialmente seu envolvimento será requerido para auxiliar na escolha das empresas-clientes que participarão da amostra dessa fase da pesquisa, bem como na identificação da pessoa mais indicada para responder à pesquisa.

O envolvimento dos executivos será novamente requerido por ocasião da análise dos resultados, que culminará com a geração do elenco de indicadores de satisfação. Os executivos das áreas de marketing e vendas da empresa, normalmente, são capazes de descodificar expressões ou jargões utilizados pelos clientes que podem ser de difícil compreensão por parte do pesquisador.

Outra contribuição dos executivos da empresa será no julgamento da adequação ou pertinência dos indicadores de satisfação gerados. Assim como os clientes, os executivos de vendas e marketing têm algo que dizer a esse respeito. A experiência os predispõe a um senso crítico apurado que, embora nem sempre prezado pelos pesquisadores, precisa ser considerado.

\section{Fase Quantitativa/Descritiva}

Nesta fase, conforme já se mencionou, será determinado o grau de satisfação dos clientes com relação aos indicadores gerados na primeira fase, justificando 
uma pesquisa de natureza quantitativa e descritiva. Os procedimentos metodológicos recomendados nessa fase da pesquisa estão a seguir apresentados.

a) População e amostra:

A população dessa fase da pesquisa deve constituir-se de clientes com experiência recente nas relações com a empresa. Tal proximidade é indispensável para que o cliente tenha mais certeza acerca dos aspectos positivos e negativos decorrentes da interação com a empresa avaliada. Julgamos que este tempo não deva exceder a seis meses. Segundo nossas avaliações em pesquisas já realizadas, quando a última compra ocorreu há mais de seis meses o cliente começa a ter dificuldades para lembrar com a devida precisão o que e como aconteceu nas suas relações com a empresa; portanto a população da pesquisa, nesse caso, é delimitada por todos os clientes da empresa que tenham realizado alguma compra nos últimos seis meses.

Antes de determinar a amostra da pesquisa, é necessário que a população seja estratificada segundo o volume de negócios. A divisão por quartil, segundo volume de negócios realizados nos últimos seis meses, pode ser um bom critério. $\mathrm{O}$ principal propósito para a estratificação da população é o de aumentar a certeza de que clientes de todos os portes serão considerados na pesquisa. Um segundo propósito é o de possibilitar análises individualizadas de cada estrato. Existem fortes razões para se acreditar que quanto maior o cliente maior deverá ser a preocupação da empresa em mantê-lo satisfeito. Uma pesquisa que contemple os diferentes estratos da população estará, portanto, agregando melhores informações para que a empresa controle os níveis de satisfação de seus clientes, bem como para que encaminhe as necessárias ações corretivas, se for o caso. Importante salientar que esse critério deve ser utilizado para cada unidade de negócio da empresa, quando ela estiver assim estruturada.

Tendo-se estratificado a população, o passo seguinte consiste em se extrair amostras em cada quartil da população de clientes de cada unidade de negócio da empresa. Nas pesquisas de satisfação que temos realizado, procuramos trabalhar com um número mínimo de 30 casos válidos em qualquer unidade de análise, o que, dependendo da situação, pode resultar em amostras que chegam a milhares de casos válidos.

Em pesquisa realizada para um grupo do setor de comunicações, que opera quase 50 veículos de comunicação, trabalhou-se com 3.700 casos válidos, o que resultou numa média de 74 casos por veículo, tendo-se condições ainda de avaliar, para cada veículo, dois estratos de clientes, segundo seu porte. Em outra pesquisa ligada a serviços de saúde que opera 6 unidades de atendimento ao público e têm cerca de 4.000 médicos cadastrados, trabalhou-se com um número de casos válidos de 860 usuários finais e 760 médicos. 
b) Coleta de dados:

Dentre as técnicas de coleta de dados disponíveis para este tipo de pesquisa, duas, na nossa opinião, merecem destaque: a entrevista pessoal e a remessa do questionário pelo correio. Ambas apresentam vantagens e desvantagens. A entrevista pessoal permite que se esclareçam as dúvidas do respondente no ato, como também propicia um índice de retorno consideravelmente melhor do que a coleta pelo correio.

Por outro lado, quando os elementos da amostra se encontram dispersos geograficamente, a coleta via questionário pelo correio pode ser recomendável, uma vez que o custo unitário de cada entrevista pessoal tende a ser, nesses casos, muito elevado. Outra situação que pode representar vantagem da coleta pelo correio em relação à entrevista pessoal, é quando o número de elementos da amostra é muito alto. Nestes casos o controle da equipe de entrevistadores, necessários para a realização dos trabalhos de campo, pode tornar-se muito complexo e vulnerável.

Se considerarmos, no entanto, somente o controle amostral, que se refere ao grau em que a amostra inicialmente projetada para a pesquisa foi efetivamente atingida, a entrevista pessoal apresenta vantagens sobre o questionário remetido pelo correio.

Em pesquisas de satisfação de clientes, a garantia de sigilo tem efeitos positivos tanto na sinceridade, quanto nos índices de devolução de respostas. Neste particular, o questionário remetido pelo correio apresenta enorme vantagem sobre a entrevista pessoal.

Pesando todos os aspectos acima, temos optado, em nossas pesquisas de satisfação de clientes, pelo questionário remetido pelo correio como forma de coleta de dados. Para melhorar o controle sobre a amostra e obter índices aceitáveis de retorno, temos utilizado os procedimentos descritos no itens $\mathbf{c}, \mathbf{d}$, e e abaixo.

c) Identificação de respondentes:

Empresas não respondem à pesquisa, mas sim as pessoas que as representam. Sendo assim, é importante que se identifique quem melhor possa expressar a satisfação, ou insatisfação, com a empresa ofertante avaliada. Nessa tarefa, os executivos das áreas de marketing e vendas, conforme já vimos no item $\mathbf{d}$ da fase qualitativa, podem emprestar importante colaboração. O rigor científico, no entanto, recomenda que não se deve ficar só com a indicação de executivos para a identificação de respondentes.

Embora oneroso nos aspectos de custo e de tempo, é recomendável que o pesquisador faça um contato preliminar, preferencialmente por telefone, para certificar-se da real condição que a pessoa indicada tem de representar sua empresa na 
resposta a pesquisas de satisfação. Nesse contato deve-se avaliar o envolvimento da pessoa com a empresa avaliada, bem como a abrangência de seu conhecimento acerca dos indicadores de satisfação utilizados na pesquisa.

A prévia identificação da pessoa certa para responder à pesquisa ainda é mais relevante em casos de coleta feita por questionários enviados pelo correio. Correspondências em nome da empresa, sem a identificação de uma pessoa responsável, principalmente em se tratando de pesquisa, têm o poder de encurtar a distância entre a mesa de trabalho e o lixo, reduzindo sensivelmente os índices de retorno.

d) Pré-notificação:

A pré-notificação refere-se à um contato prévio com a pessoa que vai responder à pesquisa. Este contato pode ser feito via correspondência personalizada ou via telefone. Nossa experiência tem demonstrado que o segundo meio é mais eficaz.

A pré-notificação tem como propósito básico informar o respondente acerca da pesquisa a ser realizada pela empresa; no entanto seus efeitos vão muito além disso. O contato prévio serve também para lhe demonstrar a importância da pesquisa, bem como nosso empenho em contar com sua resposta.

O teor da correspondência ou do telefonema de pré-notificação deve expressar os objetivos da pesquisa, como também solicitar a colaboração do respondente, aproveitando para informá-lo quanto à necessidade e relevância de seu apoio para o sucesso da pesquisa.

Em caso de correspondência, é recomendável que ela seja assinada pelo executivo de mais alto escalão da empresa avaliada. Se o contato for feito por telefone, provavelmente não será o mais alto executivo que o fará, mas quem o fizer deverá fazê-lo em nome deste.

A pré-notificação deve ser recebida pelo respondente com um prazo de, no máximo, 5 a 7 dias antes do recebimento do questionário ou da visita do entrevistador.

e) Coleta via questionário enviado pelo correio:

Quando a coleta de dados é feita via remessa do questionário pelo correio, alguns cuidados adicionais precisarão ser tomados para melhorar os índices de retorno:

- o questionário deverá ser acompanhado de uma correspondência de encaminhamento, preferencialmente assinada pelo executivo de mais alto escalão da empresa avaliada, assim como já aconteceu na correspondência de pré-notificação. Nessa correspondência deve-se expressar, novamente, os objetivos da 
pesquisa e a solicitação da colaboração do respondente, estipulando um prazo para devolução da resposta. Na nossa opinião este prazo não deve exceder a 10 dias;

- quem responde à pesquisa nos está prestando um importante serviço. Não é justo, portanto, que para fazê-lo precise ainda incorrer em despesas. Por outro lado, se as despesas decorrentes da devolução do questionário respondido ficarem a cargo do respondente, as chances de retorno podem ser drasticamente reduzidas. Deverá ser providenciada, portanto, uma devolução tipo carta resposta comercial $^{(3)}$;

- follow-up: vencido o prazo estipulado para a resposta, é recomendável que seja feito um reforço, que denominamos de follow-up. Este procedimento consiste em novo contato com a pessoa para a qual o material de pesquisa foi encaminhado e objetiva ratificar a importância da colaboração do respondente para que a pesquisa tenha êxito. É bem provável, também, que ele não esteja mais de posse do material de pesquisa, ou então, que nem sequer o tenha recebido. Em função disso, recomenda-se que o follow-up seja acompanhado de nova remessa do material de pesquisa.

Novamente este contato pode ser feito via correspondência ou telefone. Sempre que possível, deve-se dar preferência ao segundo meio.

Nota: Adotando os procedimentos acima temos obtido índices de retorno de aproximadamente $30 \%$ nas pesquisas de satisfação de clientes nas quais utilizamos questionários remetidos pelo correio como técnica de coleta.

f) Escala para mensuração da satisfação de clientes:

Quando se trata de escolher a escala para mensuração de atitudes em pesquisas de marketing, se está longe de obter consenso entre os pesquisadores. Muitas questões costumam perturbar a mente do pesquisador. Por exemplo: Qual o número ideal de categorias da escala? (3,5,7 ou 10? É melhor utilizar número par ou ímpar de categorias? As categorias devem ser numeradas ou não? Devem ser nominadas ou não? Deve-se utilizar uma escala balanceada ou não balanceada? etc). No item sobre As Escalas de Medição da Satisfação dos Clientes, na fundamentação teórica deste artigo, já comentamos suficientemente essa questão.

Estudando as diversas alternativas possíveis, em nossas pesquisas de satisfação de clientes, optamos pela escala intervalar de cinco pontos ${ }^{(4)}$. Nas escalas de intervalo os números nos dizem a posição e/ou quanto as respostas diferem entre si em relação a determinadas características ou elementos. Essa característica das escalas de intervalo nos permite comparar diferenças entre as variáveis medidas, embora não nos permita concluir quanto à magnitude absoluta das medições. 
As escalas intervalares, portanto, são apropriadas para a mensuração de variáveis para as quais não existe um zero absoluto, que é o caso da satisfação de clientes. $\mathrm{O}$ zero pode ser arbitrado. Poderíamos dizer que um cliente está totalmente insatisfeito, quando atribui grau $10,2,1$, zero, $-1,-2$ ou -10 na escala, dependendo de qual foi o número arbitrado para representar tal estado de insatisfação. Isto nos permite concluir que as escalas intervalares aceitam transformações sem perder sua propriedade.

Com cinco pontos, a escala intervalar oferece um ponto de quebra entre satisfação e insatisfação bem definido: dois pontos extremos, um caracterizando estado de totalmente satisfeito, e outro de totalmente insatisfeito; e dois pontos intermediários, um entre o ponto de quebra e o extremo de satisfação e o outro entre o ponto de quebra e o extremo de insatisfação. As cinco categorias oferecem, dessa forma, alternativas para que o cliente expresse total ou parcial satisfação, estado indefinido entre satisfação e insatisfação, e total ou parcial insatisfação.

Com base nessa escala, podem-se obter resultados avaliados sob dois aspectos:

1. número ou percentagem de clientes satisfeitos, aqueles que estão acima do ponto de quebra da escala (3); e número ou percentagem de clientes insatisfeitos, aqueles que estão abaixo do ponto de quebra (3);

2. intensidade de satisfação/insatisfação: os diferentes pontos da escala correspondem a diferentes graus de intensidade de satisfação ou insatisfação. Como este tipo de escala aceita transformações sem que perca suas propriedades, os seus cinco pontos poderão ser transformados para que expressem magnitudes decimais. Pode ser transformada em 10 pontos, multiplicando-se cada ponto por 2, ou em 100 pontos, multiplicando-se cada ponto por 20, o que permite um raciocínio percentual da intensidade de satisfação dos clientes. Esse último procedimento é o que temos utilizado em nossas pesquisas, seguindo o que recomenda a literatura consagrada sobre o tema (Marr e Crosby, 1993).

g) Tratamento dos dados:

Para analisar e interpretar os resultados desta fase quantitativa das pesquisas de satisfação de clientes que realizamos, temos utilizado, além da análise descritiva, baseada em valores absolutos e percentuais, procedimentos estatísticos baseados principalmente em análise fatorial e regressão múltipla. A primeira com vistas a agrupar indicadores de satisfação estatisticamente correlacionados e a segunda com vistas a avaliar a capacidade de explicação de cada indicador de satisfação sobre a avaliação de satisfação geral com a empresa. 


\section{CONCLUSÓES}

A pesquisa de satisfação de clientes é um imperativo para o estudo e a prática de marketing e de comportamento do consumidor.

Vivemos um ambiente empresarial, cujos fatores de entrega de valor para os acionistas mudaram, como apontou Sheth (1996) no Faculty Consortium sobre marketing estratégico, promovido pela American Marketing Association (A.M.A.). A competição global, os processos de fusões, aquisições e alianças, a redução de fornecedores, a maior seletividade dos clientes, a administração do risco, as barreiras internacionais à entrada e à saída, a capitalização em mercados globais, a integração global da empresa e as compras globais moldam um cenário em que as atividades das empresas devem ser cada vez mais sensíveis ao mercado (Sheth, 1996). Todos os desempenhos empresariais precisam responder pronta e competentemente aos requerimentos dos clientes. Até mesmo as commodities, que representam a velha pedra no sapato do marketing, vêm-se tornando cada vez mais acompanhadas de serviços, tentando diferenciar, no limite do possível, a sua oferta.

Outra evidência da importância e oportunidade do tema é sua inclusão nas prioridades de pesquisa do Marketing Science Institute (MSI) para o triênio 19961998. O interesse de pesquisa pelos processos de medição da satisfação dos clientes aparece no Priority Topic 1 (Capital Topic) - Customers and Consumers. Vale lembrar que o MSI definiu quinze prioridades para o referido triênio. A mais destacada (o capital topic) é, justamente, clientes e consumidores, em que se inscreve a medição de satisfação de clientes.

Portanto a resposta da empresa aos movimentos do mercado passa pela pesquisa de satisfação de clientes.

No presente artigo, o exame do estado-da-arte sobre a pesquisa de satisfação de clientes alimentou a concepção do método brasileiro apresentado pelos autores. Considerando tal fundamentação teórica, pode-se enquadrar o método:

- na perspectiva de análise de nível micro: a ótica da empresa, quando decide criar um sistema de avaliação da satisfação de seus clientes;

· nos estudos de perspectiva agregada sobre satisfação de clientes;

- na visão cumulativa da satisfação do cliente;

- na avaliação do desempenho da empresa sem a necessidade de avaliar também as expectativas do cliente. 
O método baseou-se, também, no exercício de benchmarking feito pelos autores, em 1994, junto a empresas de excelente reputação na realização de pesquisas sistemáticas de satisfação de clientes no Brasil. Assim, igualmente respeitaram-se as consideradas melhores práticas empresariais brasileiras de pesquisas de satisfação de clientes para desenvolver o método.

Tem-se, com base nessas inspirações, o método brasileiro de pesquisa de satisfação de clientes. Entenda-se, aqui, que brasileiro não significa inédito no país, o primeiro ou o único método que pesquisa a satisfação de clientes em nosso meio. Significa o produto combinado de uma acurada e atualizada reflexão teórica (o estado-da-arte) com uma consagrada prática empresarial no Brasil (conhecida pelo benchmarking feito em 1994), devidamente temperado pelas experiências de ensino, pesquisa e consultoria dos autores. A já representativa aplicação do método em empresas nacionais e uma prévia discussão dele em fórum acadêmico internacional (Rossi e Slongo, 1995) constituíram, complementarmente, o impulso motivacional básico para que buscássemos uma análise ampliada, acadêmica e brasileira desse método brasileiro de pesquisa de satisfação de clientes.

\section{Limitações do Trabalho}

A aplicação do método em número ainda pequeno de setores de atividade traz uma limitação referente à extensão da utilidade do método para outros setores. A continuidade de sua aplicação reforçará sua estrutura e seus procedimentos.

A confidencialidade das informações obtidas nessas pesquisas, por se tratar de trabalhos de empresas privadas, não nos permitiu apresentar os resultados e discuti-los com maior profundidade nesse artigo.

\section{IMPLICAÇÓES Futuras}

O método apresentado neste trabalho deve passar, futuramente, pelos necessários testes de validade (via análise fatorial) e confiabilidade (via coeficiente alpha de Cronbach) para sua multiplicação no meio acadêmico.

Pesquisar o grau de utilização de pesquisas de satisfação de clientes no Brasil, bem como sua importância estratégica e operacional para as empresas, constitui desdobramento natural deste artigo. Uma verificação interessante seria com empresas que estão envolvidas com programas de qualidade total, em função de tudo o que foi comentado nas justificativas do trabalho. 
Avançar na direção do aproveitamento dos resultados das pesquisas de satisfação de clientes, para aprimorar as ações de marketing das empresas, como resposta efetiva às demandas expressas pelo mercado, eis uma potencial investigação futura.

Abrir caminho para a construção de um índice nacional de satisfação de clientes, à semelhança dos índices sueco, norte-americano, alemão, neozelandês e de Taiwan, mais do que uma simples implicação, impõe-se como ponderável desafio aberto aos pesquisadores de marketing no Brasil.

\section{NOTAS}

${ }^{1} \mathrm{O}$ número ideal de participantes de um group discussion pode variar de 8 a 12.

${ }^{2}$ Uma sala de espelhos é o local mais adequado para condução dos trabalhos. Consiste em ambiente onde se realiza a sessão e de outro ambiente onde se localizam os observadores. Os dois ambientes são separados por um vidro espelhado em uma das faces, permitindo que os observadores assistam à sessão sem serem percebidos.

${ }^{3}$ A remessa de um envelope já selado ao respondente, para ser utilizado na devolução do questionário, melhora o índice de retorno em relação à carta resposta comercial. Isto foi por nós comprovado através de pesquisas que realizamos para testar influências nos índices de retorno. Este procedimento, no entanto, é vetado pelos correios, por caracterizar remessa de valores.

${ }^{4}$ Escala utilizada:

Totalmente Insatisfeito Totalmente Satisfeito

\section{$1[$ ] $2[$ ] $3[$ ] $4[$ ] 5 [ ]}

\section{ReFERÉNCIAS BibLIOGRÁFICAS}

ANDERSON, E. W.;

FORNELL, C.;

LEHMANN, D. R.

Customer satisfaction, market share, and profitability : findings from Sweden. Journal of Marketing, v. 58, p. 53-66, July 1994.

BOSS, J.-F. et al.

Satisfaction des clients et qualité totale : une recherche exploratoire sur les pratiques managériales, leurs déterminants, et leurs résultats. Les Cahiers de Recherche, CR 508, 1994.

BOULDING, W. et al.

A dynamic process model of service quality: from expectations to behavioral intentions. Journal of Marketing Research, v. 30, p. 07-27, Feb. 1993. 
CRONIN JR. J. J.;

TAYLOR, S. A.

Measuring service quality : a reexamination and extension. Journal of Marketing, v. 56, p. 55-68, July 1992.

DAY, R. L.

The next step : commonly accepted constructs for satisfaction research. In: DAY, R. L.; HUNT, H. K. New findings on consumer satisfaction and complaining behavior. Bloomington : Indiana University Press, 1982.

EPSTEIN, S.

The stability of behavior II implications for psychological research. American Psychologist, v. 35, n. 9, p. 790 806, 1980.

EVRARD, Y.

La satisfaction des consommateurs : etat des recherches. Groupe HEC, Working Paper, 1994.

FORNELL, C.

A national customer satisfaction barometer : the swedish experience. Journal of Marketing, v. 56, p. 06-21, Jan. 1992.

FORTUNE.

Americans can't get no satisfaction. Dec. 1995.

FUNDAČ̃̃ PARA O PRÊMIO NACIONAL DE QUALIDADE.

Critérios de excelência : o estado da arte da gestão para a excelência do desempenho. São Paulo, 1997. p. 17.

GRAPENTINE, T.

Problematic scales. Marketing
Research, v. 6, n. 4, p. 08-13, 1994.

HUNT, H. K.

CS/D - overview and future research direction. In: Conceptualization and measurement of consumer satisfaction and dissatisfaction. Cambridge : Marketing Science Institute, 1977.

JOHNSON, M. D.

The four faces of aggregation in customer satisfaction research. Advances in Consumer Research, v. 22, p. 89-93, 1995.

JOHNSON, M. D.;

ANDERSON, E. W.; FORNELL, C.

Rational and adaptive performance expectations in a customer satisfaction framework. Journal of Consumer Research, v. 21, p. 695-707, Mar. 1995.

MARKETING RESEARCH.

v. 6, n. 4, 1994.

MARKETING

INSTITUTE.

SCIENCE

Research priorities : a guide to MSI research programs and procedures 1996-1998.

MARR, S. L.;

CROSBY, L. A.

Customer satisfaction measurement : a management information system for total quality. Chicago : American Marketing Association, 1993.

MENTZER, J. T.;

BIENSTOCK, C. C.;

KAHN, K. B.

Benchmarking satisfaction. Marketing Management, v. 4, n. 1, p. 41-46, Summer 1995. 
REICHHELD, F. F.;

SASSER, W. E.

Zero defections : quality comes to services. Harward Business Review, v. 68, p. 105-111, Sept./ Oct. 1990.

ROSSI, C. A. V.;

SLONGO, L. A.

Customer satisfaction measurement : a brazilian experience in the sector of communications. In: FRONTIERS IN SERVICES CONFERENCE (1995: Nashville). Proceedings... Nashville : 1995.

SHETH, J. N.

Evolution of global marketing and the relationship imperative. In: AMERICAN MARKETING ASSOCIATION SIXTEENTH FACULTY CONSORTIUM ON STRATEGIC MARKETING MANAGEMENT (1996: Scottsdale). Proceedings... Scottsdale : 1996.
TEAS, R. K.

Expectations, performance evaluation and consumers' perceptions of quality. Journal of Marketing, v. 57, p. 18-34, Oct. 1993.

Expectations as comparison standard in measuring service quality : an assessment of a reassessment. Journal of Marketing, v. 58, p. 132-139, Jan. 1994.

VAN RAAIJ, W. F.

Economic psychology. Journal of Economic Psychology, n. 1, p. 01-24, Mar. 1981.

WÄRNERYD, K.-E.

Economic psychology as a field of study. In: VAN RAAIJ, W. F.; VAN VELDHOVEN, G. M.; WÄRNERYD, K.-E. Handbook of economic psychology. Dordrecht, 1988.

YI, Y.

A critical review of customer satisfaction. In: ZEITHAML, V. A. Review of marketing 1990. Chicago : A.M.A., 1991. 